\section{Kraft leads MRS Board of Directors for 2015}

www.mrs.org/board
2008, he is one of the elected referees for the DFG (German Research Foundation) in the area of materials science and engineering. For MRS, he served as Meeting Chair for the 2005 MRS Spring Meeting and has been a member of the Board of Directors since 2011. In 2014, Kraft served as MRS vice president/ president-elect.

\section{Kristi Anseth \\ Vice President/President-Elect}

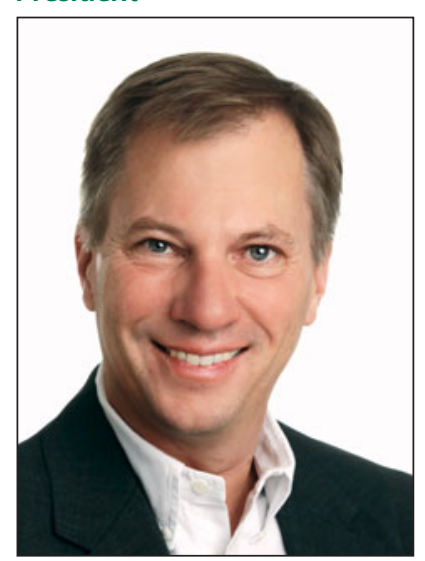

Oliver Kraft is Director at the Institute for Applied Materials and jointly Robert Bosch Professor for Nanostructured Functional Materials at the Karlsruhe Institute of Technology (KIT) in Germany. Since 2011, Kraft is also speaker of the Helmholtz-Program Science and Technology of Nanosystems. His research interests focus on studying deformation and degradation mechanisms in nanomaterials for a wide range of applications, from microelectromechanical systems and microelectronics to energy conversion and storage. Kraft graduated from the University of Stuttgart in 1995 in physical metallurgy. From 1996 to 1997, he was a postdoc at Stanford University. He also worked as a research scientist at the Max-Planck-Institut für Metallforschung in Stuttgart from 1997 to 2002. He has authored or co-authored more than 200 articles. Kraft is active in several national and international materials science societies. He has co-organized more than 20 international symposia and meetings and is currently one of the coordinators of the committee for Functional Materials of the German Materials Research Society (DGM). Since

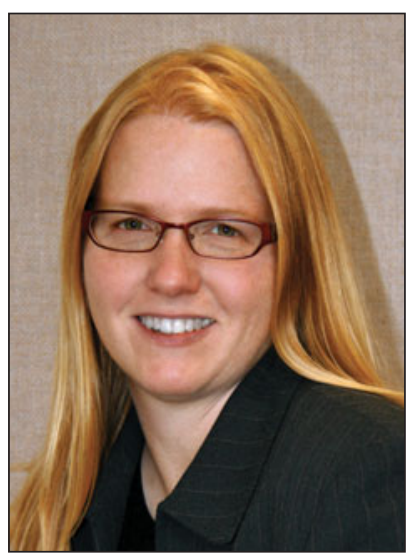

Kristi Anseth is a Howard Hughes Medical Institute Investigator and Distinguished Professor of Chemical and Biological Engineering at the University of Colorado Boulder. She earned her BS degree from Purdue University in 1992 and her $\mathrm{PhD}$ degree from the University of Colorado in 1994. She then conducted postdoctoral research at the Massachusetts Institute of Technology as a National Institutes of Health (NIH) Fellow and subsequently joined the Department of Chemical and Biological Engineering at the University of Colorado Boulder as an assistant professor in 1996. Her research interests lie at the interface between biology and engineering, where she designs new biomaterials for applications in drug delivery and regenerative medicine. She is an elected member of the US National Academy of Engineering (NAE) (2009), the Institute of Medicine (2009), and the National Academy of Sciences (2013). She is also a Fellow of the American Association for the Advancement of Science, the American Institute for Medical and Biological Engineering, and MRS. Anseth serves as an associate editor for Biomacromolecules, Progress in 
Materials Science, and Biotechnology and Bioengineering, as well as on the Board of Governors for Acta Materialia, Inc. She serves on the Advisory Council for the National Institute for Biomedical Imaging and Bioengineering of the $\mathrm{NIH}$ and is the chair of the US NAE Frontiers of Engineering Program. Anseth has been an organizer of MRS symposia, presided as a meeting chair for the 2009 MRS Fall Meeting, and was elected to the MRS Board of Directors in 2003, where she also served as chair of the Strategic Planning Committee. She has been recognized with the MRS Outstanding Young Investigator Award (2001) and the inaugural Mid-Career Research Award (2012).

\section{Tia Benson Tolle}

Immediate Past President

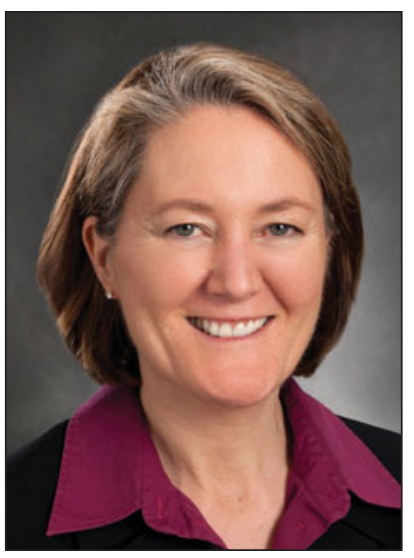

Tia Benson Tolle is Director of Advanced Materials in Boeing Commercial Airplane's Innovation Center \& Technology. In this position she has responsibility for a targeted technology portfolio spanning metals, composites, finishes, and assemblies for product development. She holds a BS degree in mechanical engineering from the University of Washington and $\mathrm{MS}$ and $\mathrm{PhD}$ degrees in materials engineering from the University of Dayton. Previously, she held the position of Technology Director of the Nonmetallic Materials Division at the Air Force Research Laboratory's Materials and Manufacturing Directorate. Her research focus has been on advanced polymeric composite materials and has spanned basic research through transition to aerospace weapons systems, working with academia, industry, government, and international collaborations. She has held several technical leadership positions within Air Force Research Laboratory's Materials and Manufacturing Directorate, has worked as a composites structures engineer at the Composites Advanced Development Program Office, Flight Dynamics Laboratory, Wright Laboratory, and has served as an instructor in the Space Shuttle Flight Training Division, Johnson Space Center, NASA. Benson Tolle has been active on several MRS committees and has served as a symposium organizer. She is also a Fellow in the Society for the Advancement of Material and Process Engineering (SAMPE). She served as SAMPE Executive Cabinet Officer (1998-2005) and as the International President (20052006). In 2014, Benson Tolle served as MRS president.

\section{Sean J. Hearne \\ Secretary}

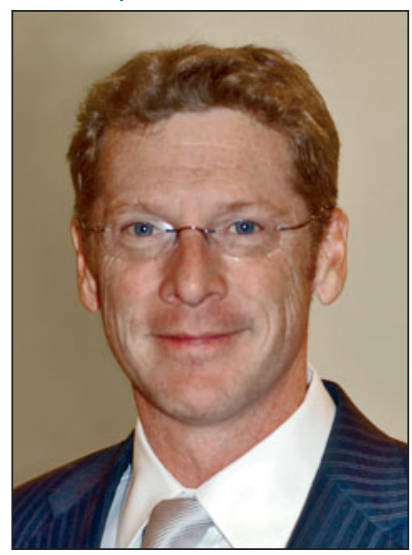

Sean J. Hearne is currently Science Staff Manager in the US Department of Energy's Center for Integrated Nanotechnologies located at Sandia National Laboratories. He received his $\mathrm{PhD}$ degree in solid-state physics from Arizona State University in 2000. He worked from 2000 to 2001 at Intel Corporation, where he was a senior process engineer in the Components Research Group in Hillsboro, Ore. Since 2001, Hearne has worked for Sandia National Laboratories. His research has primarily focused on the sources of intrinsic stress creation and evolution during thin-film deposition, and has been well cited in the area of metal-organic chemical vapor deposition growth of $\mathrm{GaN}$ and in the fundamental mechanisms inducing stress during Volmer-Weber thinfilm growth. This work led him into other research topics, including micro- and nano-fabrication and nano-enabled devices for electrical energy storage. Hearne's current interests focus on enabling new programs to develop novel in situ techniques for the study of high energy and power density systems. He has been active in the MRS community since attending his first MRS Meeting in 1995 as a graduate student. Over the years, he has presented, organized symposia, and served on a number of committees and task forces, and he has chaired the MRS Information Services Committee, which oversees all of the MRS print and online publications, including the MRS Bulletin, Journal of Materials Research, and the MRS Symposium Proceedings.

\section{Michael R. Fitzsimmons \\ Treasurer}

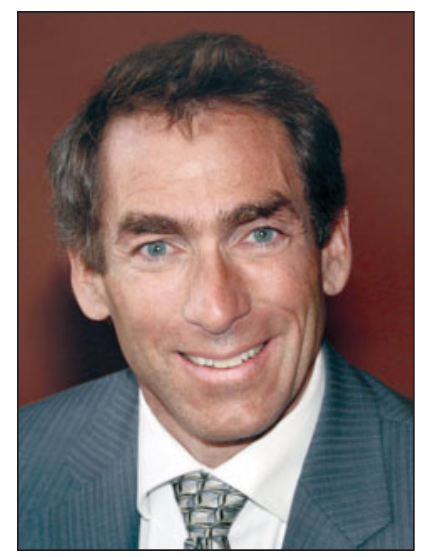

Michael R. Fitzsimmons is a research scientist at the Center for Integrated Nanotechnologies, Los Alamos National Laboratory. He received a BA degree in physics from Reed College (1982) and a PhD degree from Cornell University (1988) in materials science and engineering. After graduation, he pursued studies of nanostructured materials with synchrotron radiation in the group of $\mathrm{J}$. Peisl, Ludwig-Maximilians-Universität München, as a Fulbright Junior Research Fellow. In 1990, Fitzsimmons joined Los Alamos. Fitzsimmons pursues research in nanostructured magnetic materials using neutron and resonant $\mathrm{x}$-ray scattering. $\mathrm{He}$ is a Fellow of the American Physical Society and the Neutron Scattering Society 
of America. He is a recipient of the Los Alamos Lab Director's Distinguished Performance Award and the Los Alamos Neutron Science Director's Award. He has authored more than 100 papers and collaborates with more than 200 scientists in fields of hard and soft matter, and x-ray and neutron scattering. Fitzsimmons has given numerous invited lectures, including neutron-scattering tutorials. He co-authored a book chapter/tutorial on polarized neutron reflectometry and recently organized a neutron-scattering school focused on magnetic materials and nanomagnetism. Fitzsimmons was a meeting chair for the 2008 MRS Fall Meeting and served as a member-at-large on the executive committee for the American Physical Society Topical Group on Magnetism and its Applications.

\section{Todd M. Osman}

Executive Director

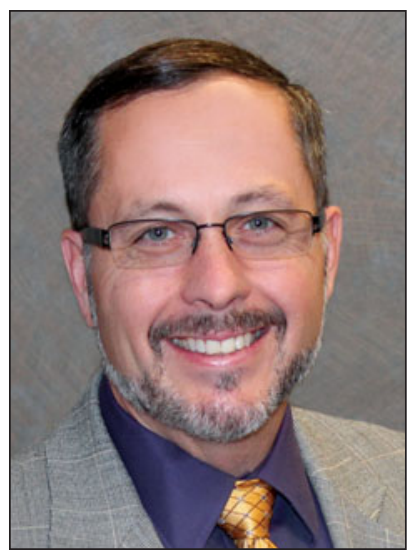

Todd M. Osman became Executive Director of MRS in September 2008. During his tenure, MRS has launched the Materials Research Society Foundation, expanded its communications and meetings portfolio, and broadened its outreach and engagement programs. Prior to joining MRS, Osman co-founded The Pennsylvania NanoMaterials Commercialization Center. He also spent 11 years at United States Steel Corporation, where he received peer and corporate recognition for his research and coordinated cooperative R\&D programs in North America, Europe, and Asia. He received his $\mathrm{PhD}$ degree in materials science and engineering from Case Western Reserve University and has authored numerous articles. Osman is a member of the Board of Directors of the Lighthouse Foundation, a non-profit charitable organization, and a member of the MRS Board of Directors.

\section{Board of Directors}

\section{Charles Black (2017)}

Black is a scientist and the group leader for electronic nanomaterials in the Center for Functional Nanomaterials, a US Department of Energy User Facility at Brookhaven National Laboratory. He manages a group of 10 scientists exploring the use of nanostructures for solar energy conversion. His research interests are in using nanostructured materials and self-assembly approaches to improve the performance of solar devices. His involvement with MRS started in 1997, and he was a 2013 MRS Fall Meeting co-chair.

\section{Alexandra Boltasseva (2016)}

Boltasseva is currently an associate professor in the School of Electrical and Computer Engineering and Birck Nanotechnology Center, Purdue University. She specializes in nanophotonics and nanotechnology focusing on optical metamaterials, nanoscale optics, plasmonics and plasmonic materials, nanofabrication, and material growth. Boltasseva has been a member of MRS since 2005, featuring six MRS meetings' presentations, including three invited talks, the 2013 MRS Outstanding Young Investigator lecture, and two invited contributions to MRS Bulletin.

\section{Jeffrey Brinker (2016)}

Brinker is currently the Distinguished and Regent's Professor of Chemical and Biological Engineering and Molecular Genetics and Microbiology, Co-Director of the Center for Micro-Engineered Materials, and a member of the Cancer Center at the University of New Mexico. $\mathrm{He}$ is one of four Fellows at Sandia National Laboratories, and a Distinguished Affiliate Scientist at the Sandia/Los Alamos National Laboratories Center for Integrated Nanotechnologies. His research focus is on processing, characterization, and understanding of porous and composite nanostructured materials and the development of novel functional bio/nano interfaces for applications in environmental microbiology and drug delivery. Brinker has co-organized over a dozen MRS symposia, where he introduced the interdisciplinary idea of "Better Ceramics Through Chemistry," and co-chaired the 1990 MRS Spring Meeting.

\section{David Cahen (2015)}

Cahen is a professor in the Materials and Interfaces Department of the Weizmann Institute of Science. He directs the Institute's alternative sustainable energy research initiative. His research focus is on bio-molecular electronics, hybrid organicinorganic interfaces and materials, and photovoltaic devices. He served as a Volume Organizer for MRS Bulletin, as well as the chair of the magazine's Energy Quarterly Department; with David Ginley, he edited the MRS/Cambridge University Press textbook on Fundamentals of Materials for Energy and Environmental Sustainability; and co-founded the MRS Energy \& Sustainability - A Review Journal. Cahen co-chaired the 2011 International Materials Research Congress. He is an MRS Fellow.

\section{Steve Eglash (2015)}

Eglash is Executive Director of the Stanford Data Science Initiative, the Artificial Intelligence Lab, and the Secure Internet of Things Project, all at Stanford University. His background is in data science, energy, cleantech, optoelectronics, and materials. His research includes basic materials, semiconductor devices, and the innovation process. He has experience in corporate management, venture capital, and engineering.

\section{Sossina M. Haile (2015)}

Haile is the Walter P. Murphy Professor of Materials Science and Engineering at Northwestern University, after 18 years at the California Institute of Technology. Her research broadly encompasses solidstate ionic materials and devices, with a particular focus on energy technologies. She was a principal editor for the Journal of Materials Research (19972001), co-organized several symposia, and currently serves as the faculty advisor for a local MRS Student Chapter. 


\section{Andrea M. Hodge (2015)}

Hodge is a professor and the Philip and Cayley MacDonald Early Career Chair in the Aerospace and Mechanical Engineering Department, with a joint appointment at the Mork Family Department of Chemical Engineering and Materials Science at the University of Southern California. Her research interests range from processing of nanocrystalline and nanoporous materials to nanomechanics of metals and biomaterials. For MRS, Hodge has served as a symposium organizer and as a chair of the 2011 International Materials Research Congress.

\section{Hideo Hosono (2016)}

Hosono is a professor in the Frontier Research Center and Materials and Structures Laboratory at the Tokyo Institute of Technology, and is a founding director of the Materials Research Center for Element Strategy. His research focuses on electroactive functionalities in transparent oxides. For MRS, he has been both an organizer and an invited speaker for various symposia.

\section{Karen L. Kavanagh (2017)}

Kavanagh is a professor of physics and an associate member of the Department of Chemistry and School of Engineering Science at Simon Fraser University. She also directs the 4D Labs Nanoimaging Facility. Her research is focused on atomic interfaces and nanostructures, with recent interest in nanocontacts, spin transport at electrodeposited metal-semiconductor interfaces, dislocations in nanowire heterostructures, magnetic measurements using electron holography, fibbed nanohole arrays, and two-dimensional materials. She has served on the MRS Membership Committee in 1993 and has co-chaired multiple MRS symposia.

\section{Fiona C. Meldrum (2015)}

Meldrum holds a chair position in Inorganic Chemistry at the University of Leeds, where her research centers on bioinspired materials chemistry. For MRS, she has served as a symposium organizer, a co-chair for the 2013 International Materials Research Congress, and as a Volume Organizer for MRS Bulletin, where she currently serves on the Editorial Board.

\section{Kornelius Nielsch (2016)}

Nielsch is a professor and vice speaker at the Institute of Applied Physics at the University of Hamburg, Germany. His research focuses on thermoelectric materials, topological insulators, and magnetic nanostructures. $\mathrm{He}$ has been a co-organizer for MRS symposia, a co-chair of the 2011 Spring Meeting, and he served on the Program Development Subcommittee.

\section{Christine Ortiz (2017)}

Ortiz is the Morris Cohen Professor of Materials Science and Engineering and the Dean for Graduate Education at the Massachusetts Institute of Technology. Her research program focuses on the multiscale mechanics of musculoskeletal and exoskeletal structural biological materials, with the primary goal being to quantify and understand new mechanisms, phenomena, and design principles and how they determine function, quality, and pathology. Ortiz has been an active member of MRS throughout her professional career.

\section{David J. Parrillo (2015)}

Parrillo is the Global R\&D Director of Packaging \& Specialty Plastics for The Dow Chemical Company and served as a 2014 MRS Spring Symposium conference chair. He previously held positions at General Electric and Air Products and Chemicals. He holds a $\mathrm{PhD}$ degree in chemical engineering from the University of Pennsylvania and a BS degree in chemical engineering from the University of Rhode Island. Parrillo is a member of the External Advisory Board at UC Santa Barbara for Chemical Engineering and the Board of Directors of the West Midland Family Center. He holds 13 US patents and has authored/coauthored 20 publications in scientific literature.

\section{Sabrina Sartori (2017)}

Sartori is an associate professor at the Physics Department of the University of Oslo, Norway. She is also the coordinator of the Energy and Environment group at the University Graduate Center at Kjeller. Her research interests cover the synthesis and characterization of materials for hydrogen storage and batteries, with a particular focus on nanoscale and porous materials investigated with small-angle neutron and $\mathrm{x}$-ray scattering, in situ synchrotron radiation, and powder neutron diffraction. In her academic role, she is engaged in the science and technology of materials for renewable energy. She is a board member of the MRS Bulletin Energy Quarterly.

\section{Eric A. Stach (2015)}

Stach is the group leader for the Electron Microscopy Group at the Brookhaven National Laboratory's Center for Functional Nanomaterials, and the Chief Technology Officer for Hummingbird Scientific, which he co-founded in 2004. The company produces advanced instrumentation for electron and ion microscopy. Stach received the MRS Silver Graduate Student Award in 1997 and has served as a guest editor for $M R S$ Bulletin, a symposium organizer, and as a chair for the 2012 Fall Meeting.

\section{Loucas Tsakalakos (2016)}

Tsakalakos is currently the manager of the Photonics Laboratory at the General Electric-Global Research Center in Niskayuna, N.Y. His research focuses on the integration of heterogeneous thin-film and nanostructured materials systems for micro- and nano-device applications, as well as on the characterization of materials. For MRS, he co-organized several symposia and served as a co-chair of the 2013 MRS Fall Meeting.

\section{Anke Weidenkaff (2017)}

Weidenkaff has been a full professor and chair for Materials Chemistry at the University of Stuttgart, Germany, since 2013. Her research interests comprise the development, synthesis, and characterization of advanced thermoelectric materials (perovskite-type oxides and oxynitrides, half-Heusler compounds, and carbon nanotube composite materials) for an efficient energy conversion. She has organized several MRS symposia and is an Editorial Board member of the MRS Bulletin and MRS Bulletin Energy Quarterly. She has been a member of the E-MRS Executive Committee since 2012 and served as one of the E-MRS Spring Meeting chairs in 2013. 
Advance your results.

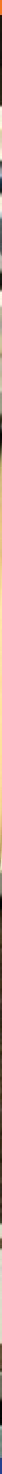

Photo of A. Zettl by Roy Kaltschmidt. Courtesy of Lawrence Berkeley National Laboratory.

(C) 2010 The Regents of the University of California, Lawrence Berkeley National Laboratory

Your research achievements deserve the undivided attention of experts in your

field, a rigorous review process, and the fastest publication time available.

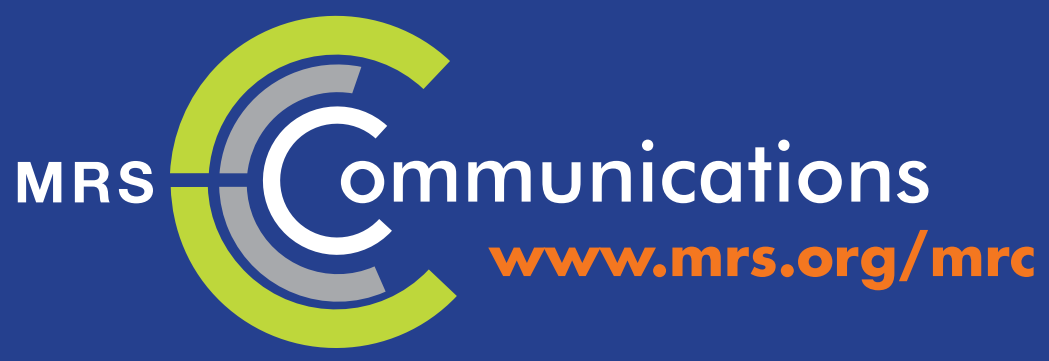

